\title{
Neurocysticercosis, familial cerebral cavernomas and intracranial calcifications: differential diagnosis for adequate management
}

\author{
Neurocisticose, cavernoma cerebral familiar e calcificações intracranianas: diagnóstico \\ diferencial e acompanhamento adequado \\ Emerson Leandro Gasparetto', Soniza Alves-Leon², Flavio Sampaio Domingues³, João Thiago Frossard³, \\ Selva Paraguassu Lopes ${ }^{4}$, Jorge Marcondes de Souza ${ }^{3}$
}

\begin{abstract}
Neurocysticercosis (NCC) is an endemic disease and important public health problem in some areas of the World and epilepsy is the most common neurological manifestation. Multiple intracranial lesions, commonly calcified, are seen on cranial computed tomography (CT) in the chronic phase of the disease and considered one of the diagnostic criteria of the diagnosis. Magnetic resonance imaging (MRI) is the test that better depicts the different stages of the intracranial cysts but does not show clearly calcified lesions. Cerebral cavernous malformations (CCM), also known as cerebral cavernomas, are frequent vascular malformations of the brain, better demonstrated by MRI and have also epilepsy as the main form of clinical presentation. When occurring in the familial form, cerebral cavernomas typically present with multiple lesions throughout the brain and, very often, with foci of calcifications in the lesions when submitted to the CT imaging. In the countries, and geographic areas, where NCC is established as an endemic health problem and neuroimaging screening is done by CT scan, it will be important to consider the differential diagnosis between the two diseases due to the differences in adequate management.
\end{abstract}

Keywords: neurocysticercosis; epilepsy; cavernomas; familial cerebral cavernous malformation; computerized tomography; magnetic resonance.

\section{RESUMO}

A neurocisticercose (NCC) é um importante problema endêmico de saúde pública em algumas áreas do mundo, sendo epilepsia sua manifestação clínica mais comum. Múltiplas lesões intracranianas, geralmente com calcificações visualizadas em tomografia computorizada de crânio, são interpretadas como um dos critérios diagnósticos na fase crônica da doença. A ressonância magnética é o melhor teste de imagem para identificar a doença em diferentes estágios de sua forma cística mas apresenta limitações para demonstrar lesões calcificadas. Malformações cavernosas cerebrais, ou cavernomas, são malformações vasculares comuns ao sistema nervoso e epilepsia é também a sua forma mais frequente de apresentação. Na sua forma familiar cavernomas apresentam-se tipicamente com múltiplas lesões encefálicas e, frequentemente, com focos de calcificações na TC. Em alguns países, e determinadas regiões geográficas, onde neurocisticercose é endêmica, a neuroimagem mais usada para diagnóstico é a TC de crânio. Nesse contexto torna-se importante estabelecer bases para o diagnóstico diferencial entre as duas doenças, devido às diferentes formas de acompanhamento e tratamento adequado.

Palavras-chave: neurocisticercose; epilepsia; malformação cavernosa cerebral familiar; cavernoma cerebral; tomografia computorizada; ressonância magnética.

\section{NEUROCYSTICERCOSIS}

Cysticercosis is the result of the infestation of the larval form of "T. solium" and neurocysticercosis (NCC) is the established involvement of the central nervous system (CNS). The disease is endemic in developing countries, more prominently in Latin America and in some regions of Asia and Africa ${ }^{1}$. NCC is also becoming an emerging infectious health problem in developed countries due to immigration ${ }^{2}$. Contamination of humans by consumption of the T. solium eggs leads to person-to-person or auto-infestation but the real prevalence of NCC is not yet established. NCC is commonly described

'Universidade Federal do Rio de Janeiro, Departamento de Radiologia, Rio de Janeiro RJ, Brazil;

2Universidade Federal do Estado do Rio de Janeiro, Departamento de Neurologia, Programa de Epilepsias, Rio de Janeiro RJ, Brazil;

${ }^{3}$ Universidade Federal do Rio de Janeiro, Departamento de Neurocirurgia, Rio de Janeiro RJ, Brazil;

${ }^{4}$ Aliança Cavernoma Brasil, Brasília DF, Brazil.

Correspondence: Jorge Marcondes de Souza; Departamento de Neurocirurgia, Universidade Federal do Rio de Janeiro; Rua Rodolpho Rocco, 255, Hospital Universitário; 25622-826 Rio de Janeiro RJ, Brasil; E-mail:Jormarcondes@gmail.com

Conflict of interest: There is no conflict of interest to declare.

Received 02 September 2015; Received in final form 16 November 2016; Accepted 22 December 2015. 
as the leading cause of epilepsy in endemic regions, although the distinction of seizures occurrence and epilepsy related to NCC has not achieved complete elucidation ${ }^{3}$. With cerebral cyst degeneration there is a contrast enhancement of the lesion surrounded by edema on CT as well as high signal images on MRI T2 sequences and gadolinium enhancement on T1 images supposedly due to inflammatory reactions ${ }^{4,5}$.

Epilepsy, in general grounds, is defined by unprovoked seizures in more than one occasion ${ }^{6}$ and usually correlates with the most probable condition directly involved on its development. Although there are evidences supporting seizures as the most common manifestation of NCC in the symptomatic patients ${ }^{7} \mathrm{NC}$ can be asymptomatic in some cases and seropositiveness through enzyme-linked immune transfer blot assay (EITB) does not always indicate active disease nor CNS involvement ${ }^{8}$. Carpio detected that the proportion of the seropositivity in epileptic NCC patients was the same reported in the general population in the same geographic areas $^{3}$. On the other hand there is a chance of dual disease, like temporal lobe epilepsy with hippocampal sclerosis and NCC, in endemic regions, being involved in the pathogenesis of epilepsy in patients diagnosed with $\mathrm{NC}$ and the differential diagnosis will only be reached by means of special neurophysiological testing9. Evidence-based data from well designed prospective studies to establish the surrogates for epilepsy due to NCC is scarce $e^{3,10,11,12}$, showing the importance of differential diagnosis with other diseases on the determination of NCC as seizures etiology and the risk of overestimation of neurocysticercosis as a prime cause of seizures.

\section{FAMILIAL CEREBRAL CAVERNOUS MALFORMATIONS (FCCM)}

Cavernous malformations are common cerebrovascular abnormalities, affecting $0.4-0.8 \%$ of the general population $^{13,14,15}$. Pathologically, CCM are defined by clusters of dilated capillary cavities, in back-to-back disposition, lined by a single layer of endothelium, lacking smooth muscle and no intervening brain parenchyma ${ }^{16}$ (Figure 1).

Cavernomas may occur in the brain or spinal cord as an isolated single lesion. The familial form of cerebral cavernomas (FCCM) is characterized by multiple brain lesions (Figure 2), usually as the result of loss-of-function mutations in one of the known CCM genes, namely CCM1 (KRIT1), CCM2 (MGC4607) and CCM3 (PDCD10) ${ }^{16}$. The pattern of inheritance of the familial form is of autosomal dominance and its proportion in the CCM population has been estimated as high as $50 \%$ in Hispanic-American patients and $10-40 \%$ in other populations $^{16,17}$. Mutations in the CCM1, CCM2 and CCM3 genes account generally for $50-65 \%, 15-19 \%$ and less than $10 \%$ of the FCCM cases, respectively ${ }^{18,16}$. In the United States, mainly in the State of New Mexico and southwestern regions, there has been described a high frequency of a Common Hispanic Mutation

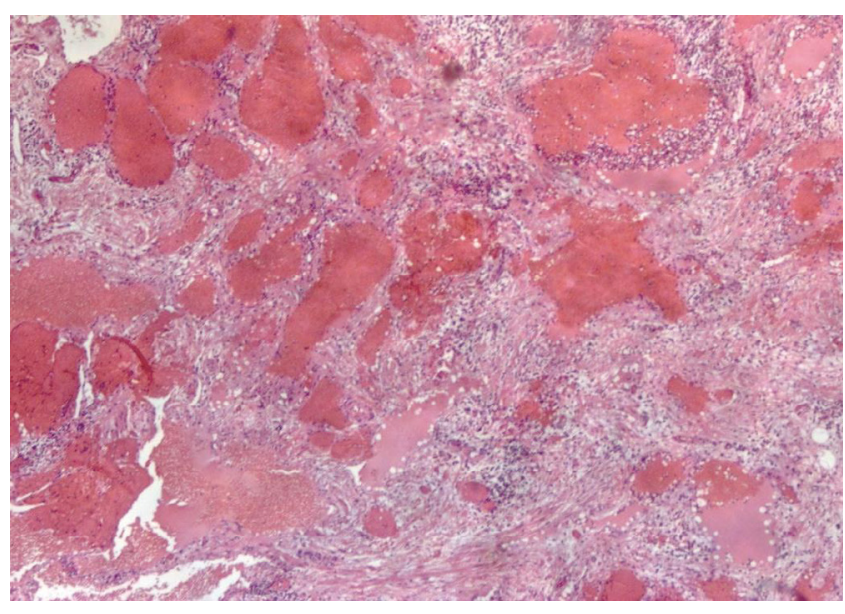

Figure 1. Cavernous malformation. Dilated capillary cavities, in back-to-back disposition, with a single layer of endothelium and no intervening brain parenchyma. HE 40X.

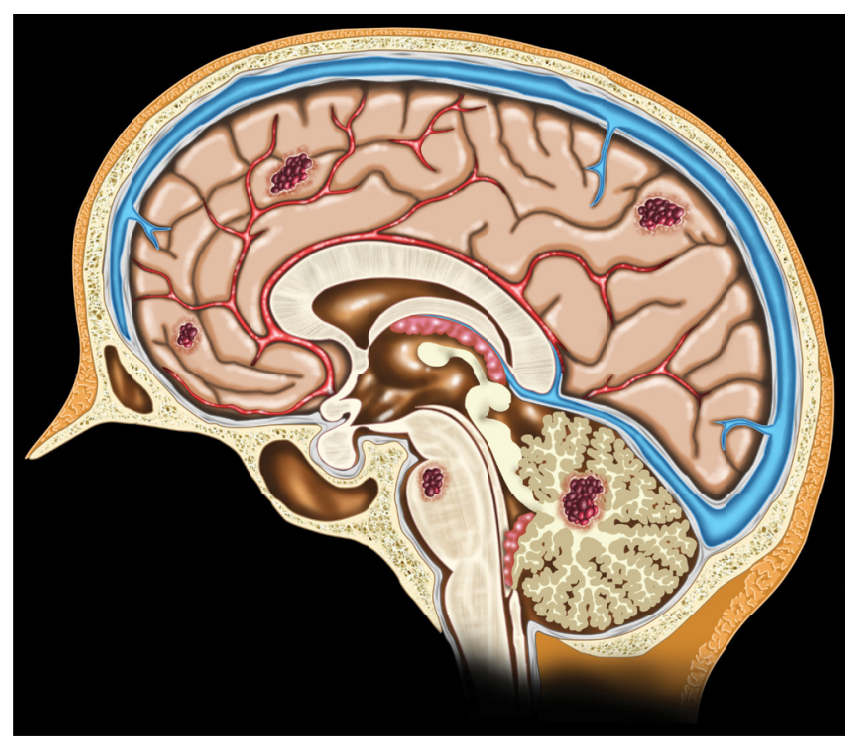

Figure 2. Schematic representation of the familial form and multiple cavernomas distributed throughout the brain. (the publication of this figure was authorized by the patient.)

of the gene CCM1/KRIT1 (Q455X, rs 267607203) in families of Mexican heritage up to the point where most insurance companies are paying for its screening ${ }^{19}$.

The New Mexico CCM cohort recently reported a study searching for association between inflammatory biomarkers and aggressiveness of the disease, with most patients having multiple lesions and epilepsy as the main symptoms ${ }^{20}$.

In an ongoing study for a Register of Disease for Cerebral Cavernomas in Brazil, the CCM cohort at the Federal University of Rio Janeiro has also detected the predominance of CCM1 mutational profile in the studied families ${ }^{21}$.

In another multicenter study it was reported a very aggressive profile of FCCM cases due to mutations of the gene $\mathrm{CCM}^{22}$, with a mean age at presentation of 12 years and an excessive lesion burden, meaning $33 \%$ of the patients having 
more than 100 lesions and $78 \%$ with more than 20 lesions. Epilepsy was also the most common symptom of this aggressive form of the disease.

Epilepsy is the more common manifestation of the cerebral cavernomas, with most studies showing seizures as leading symptom in $40 \%$ to $70 \%$ of the cases ${ }^{23,24,25}$. The mechanisms of seizures pathogenesis in CCMs are disputed but there is a literature trend toward rendering hemosiderin, from de blood products leaked from the endothelial cells junctional defect, the main cause due to its epileptogenic effect ${ }^{26,27}$.

Hemispheric cavernomas are associated with higher tendency of seizures than other mass lesions in the brain parenchyma, with the potential for evolution for refractory epilepsy in $40 \%$ of the cases $^{25}$. Al-Shahi detected, in a prospective study in Scotland that, for adults without lesional hemorrhage or focal neurological deficit, cavernomas were more frequently multiple in the patients with seizures (43\%) than in the ones without seizures $(6 \%)^{23}$.

\section{THE QUEST FOR THE NEUROIMAGING}

In the geographic areas of the world where NCC is more prevalent, CT is the more utilized imaging test and, regarding the calcifications of the late phase of the disease, it would be the neuroimaging for confirmation of diagnosis. Carpio et al. listed, in the methodology of a case control-study of cysticercosis, in Ecuador ${ }^{28}$, CT as the imaging test of choice and have described their proposed CT criteria for the lesional characterization. Alive cysts are depicted as one or more hypodense areas, variable in size and without constrast enhancement whereas the transitional ones as cysts with contrast enhacement. Inactive lesions are depicted as rounded, hypodense, without enhancement and with areas of calcification ${ }^{28}$.

MRI is the best test for definition of the cyst stage in their evolution in the brain on T1, T2, FLAIR sequences, including the inflammatory aspects when using enhanced images with gadolinium infusion (Figures $3 \mathrm{~A}, \mathrm{~B}$ and $\mathrm{C})^{29}$ although not as accurate in detection of calcifications. Diffusion weighted images were demonstrated as better defining the scolex and increasing the confidence for the NCC diagnosis by $\mathrm{MRI}^{30}$. A recent review on NCC showed that MRI findings are better predictive for the stage of the cysts and diffusion-weighted images and apparent diffusion coefficient maps allowing better demonstration of the cysticerci in their colloidal phase. Calcified cysts were described as not well depicted and there was a suggestion that more sophisticated sequences, as susceptibility-weighted protocols, would be necessary $^{9}$. Cavernous malformations, on the other hand, are not well seen on CT images, where the lesions will range from non-visualization to the mildly enhancing ones, variable format and, very often, with calcification. Batra et al.
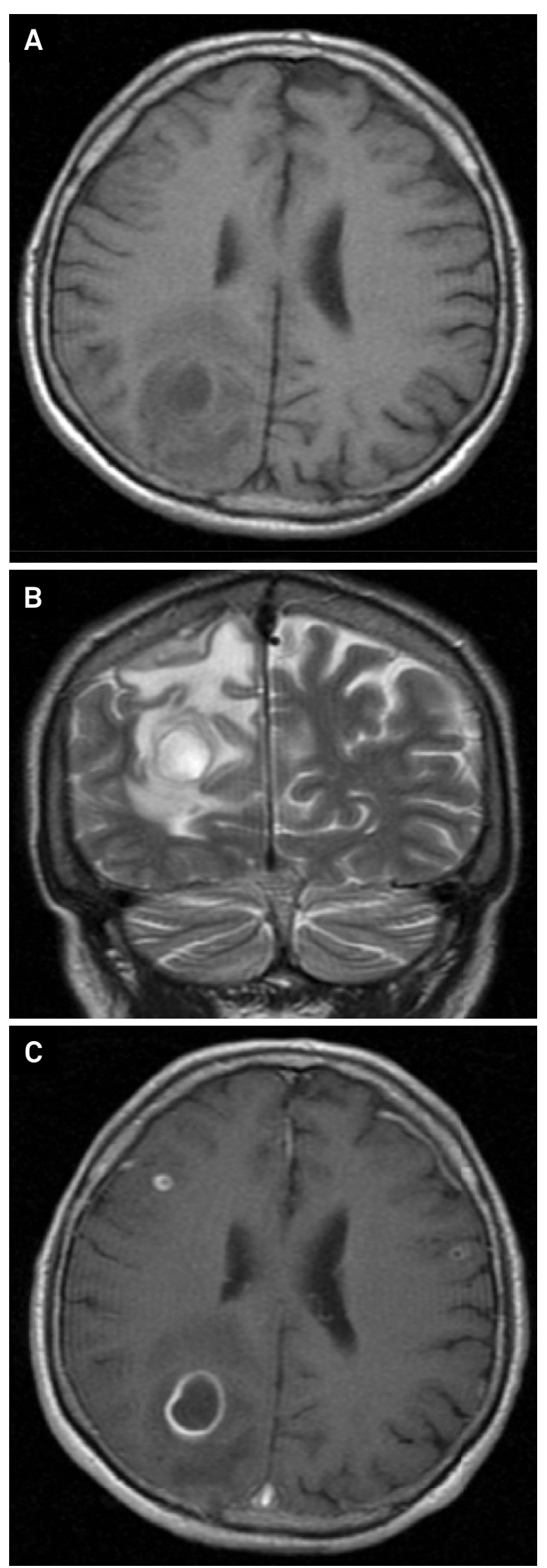

Figure 3. Axial T1 There is a round lesion with low signal on T1 (A); Coronal T2 with high signal on T2, surrounded by vasogenic edema on the Right parieto-occipital area (B); After gadolinium admnistration ring-enhancement is seen in the lesion, as well as additional small rign-enhancing lesions are demonstrated on the right and left frontal lobes (C). 
described, in their series of CCMs at the Johns Hopkins University, $58 \%$ of the specimens with thrombosis and $41 \%$ with calcifications ${ }^{31}$. MRI is the neuroimaging test of choice in CCM, with the typical pattern of "popcorn" appearance in the sequences $\mathrm{T} 1$ and $\mathrm{T} 2$ sequences, result from the mixed old and new blood residua inside the lesions, usually with hyperintense core and a hypointense dark surrounding rim $^{32}$. The sequences with higher sensitivity to the hemosiderin susceptibility effect are much more accurate in depicting the hemosiderin deposits in the lesions and the worldwide most used ones are the gradiente-echo imaging (GRE) or susceptibility-weightet imaging (SWI) sequences. We have shown that SWI sequence has superior accuracy in detecting small lesions and its usefulness in detecting familial cases of CCM and a more acurate lesional burden ${ }^{33}$.

As an example of possible misdiagnosis that an initial screening with CT scan might create we present a case of a 25-yrs-old female, with recent episode of seizures and cranial MRI test showing typical multiple cerebral cavernous malformations (Figure 4A). She was an index case of a familial form of CCM living in a small town in Brazil, in a geographic area known as endemic for cysticercosis. Her father was diagnosed as harboring neurocysticercosis for the last 30 years, and treated accordingly, based on epileptic profile and his CT scan with multiple calcifications (Figure 4B).

The multiple typical CCM lesions diagnosis of his daughter raised the high probability of familial cavernomas and, accordingly, his cranial MRI showed several characteristic cavernous lesions matching the calcified areas on CT scan (Figures 4C and D).

Likewise, many patients of the CCM cohort of the Universidade Federal do Rio de Janeiro, which has a consolidated follow-up of 22 Brazilian families, harbor multiple intracranial calcifications on CT imaging and epilepsy as the main symptoms (Figures $5 \mathrm{~A}, \mathrm{~B}, \mathrm{C}$ and D). The use of calcifications seen on cranial CT as a valid surrogate for neurocysticercosis, in those circumstances, would certainly constitute a misdiagnosis.

An interesting confounding aspect is that there are few studies showing familial aggregation of $\mathrm{NC}^{28,34}$ and, on this situation, it would be reasonable to use MRI scan to establish the differential diagnosis with FCCM. As the familial form of cavernomas is more prone to develop epilepsy ${ }^{24}$ and also characterized by multiple brain lesions, often calcified on the CT scan, ranging from a few to uncountable ones, the different nature of the two diseases certainly raises the importance the correct diagnosis.
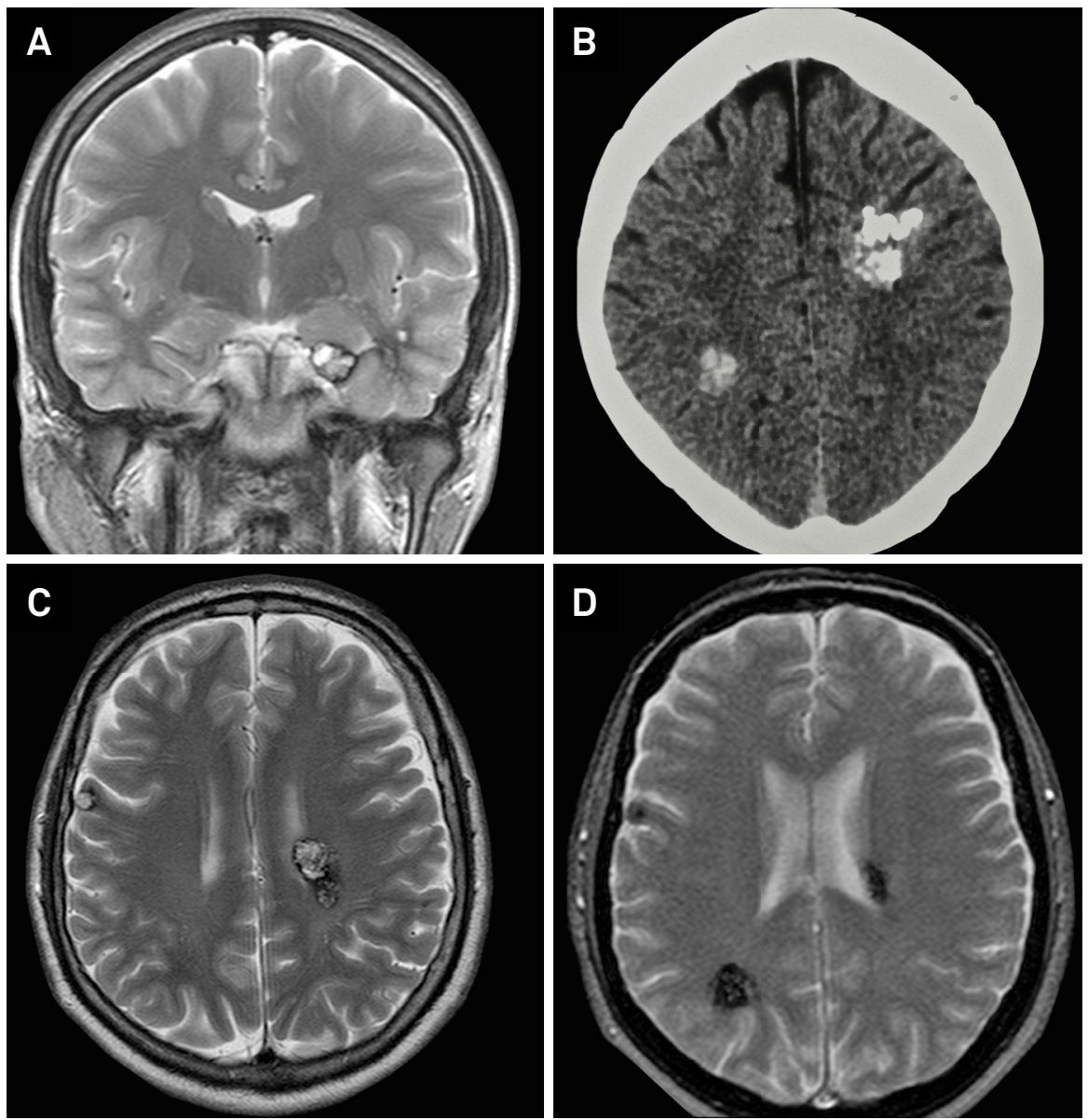

Figure 4. (A) MRI on coronal T2 image depicts two cavernous lesions at the mesiobasal and subcortical left temporal lobe (A); CTcan with calcified lesions on the right and left hemisphere (B); MRI Axial T2 imaging shows left justa-ventricular and right cortical frontal typical cavernous malformation (C); G-Echo sequence showing the lesions with usual low signal of the lesions (D). 

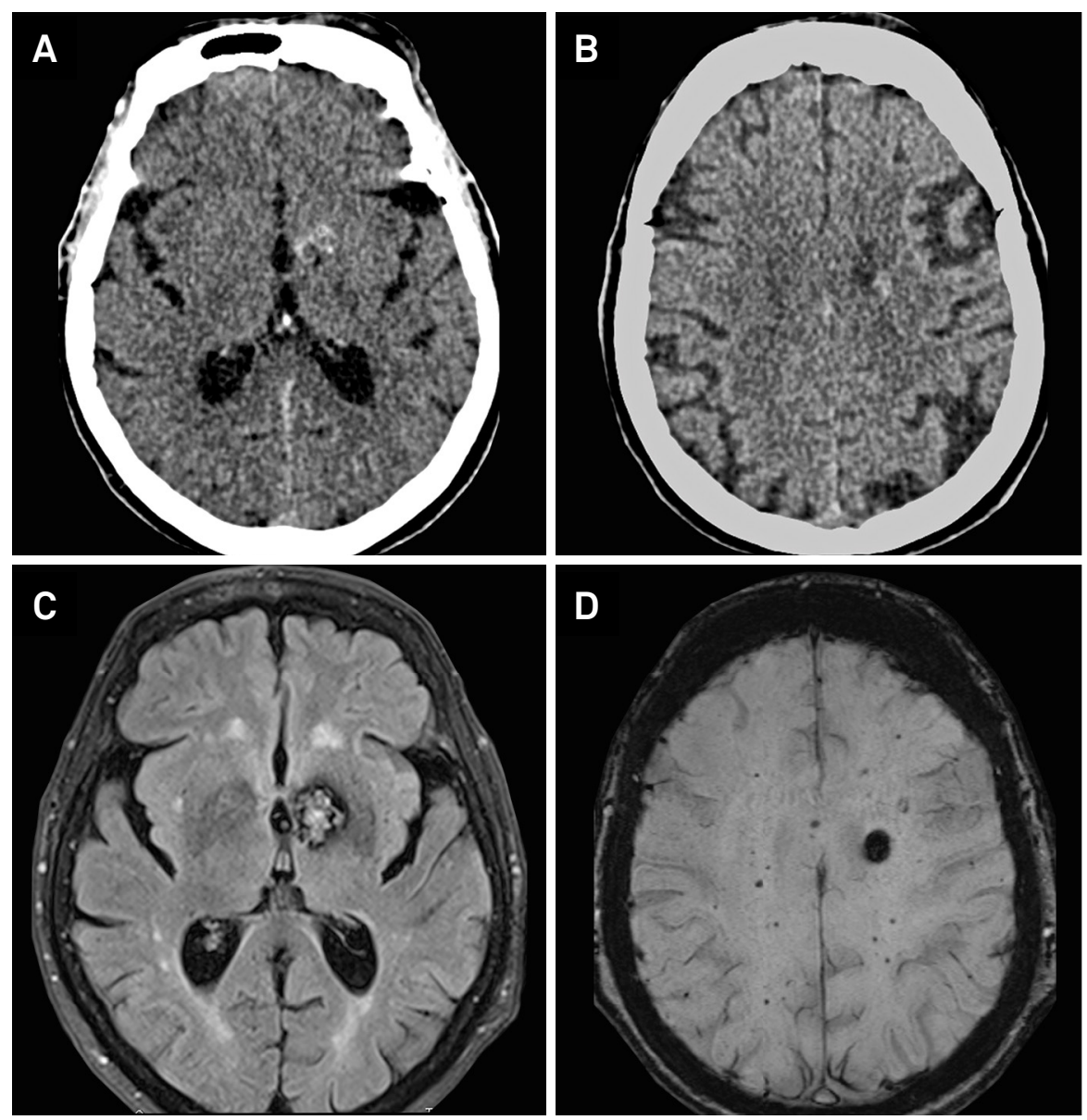

Figure 5. A CT scan image showing left basal ganglia calcification (A); Another left subcortical frontal calcification in the same patient (B); MRI FLAIR axial depicting typical cavernoma imaging at the left basal ganglia (C); More lesions detected by MR-SWI sequence than other sequences (D).

\section{CONSEQUENCES OF THE MISDIAGNOSIS}

Cavernous malformations are prone to bleeding and have a $2.4 \%$ person/year rate of lesional hemorrhage ${ }^{13}$. The prevalence on the general population is estimated on $0.4-0.8 \%$ and the familial form around $50 \%$ of them, rendering the formal diagnosis and counseling clearly an important step on management. The misdiagnosis between the NCC and FCCM has several important consequences deserving awareness of the medical and, specially, neurologic community. Patients with $\mathrm{CCM}$, erroneously diagnosed as NCC, might receive prescription of medications for NCC treatment, namely praziquantel, and submitted to unnecessary side effects. Genetic counseling on cases of familial cavernomas will not be done rendering patients unaware of the probabilities, and consequences, of their offsprings having the disease. Likewise, the suggestion for annual/bi-annual MRI checking for new lesions or biological changes in the known CCMs will not be made.

Prevention of intracranial bleeding in CCM patients usually includes counseling to avoid medications such as AAS or any other anti-thrombotic drugs, as well as anticoagulants, like coumadin, heparin or heparinoids, and this will not be done having the misdiagnosis of neurocysticercosis been made ${ }^{35,36}$.

In conclusion, with the widespread access to the MRI technology it might be worthwhile to consider reviewing the prevalent paradigm for NCC diagnosis, when calcified cysts are detected in cranial $\mathrm{CT}$ in patients suffering from seizures in endemic areas. Cavernous malformations are lesions that bleed spontaneously, leading to the risk of intracranial hemorrhage. In its familial form, with multiple lesions and frequent calcification, there are real chances for being confounded with calcified cysts due to NCC when cranial image done only by CT scan.

Although MRI notoriously does not clearly detect calcification, it is the best neuroimaging test of choice for correct diagnosis of cerebral cavernous malformation, including the SWI or GRE for detection of familial form, and NCC.

In the geographical areas where NCC still prevails as an important endemic health problem the differential diagnosis with familial cavernous malformations should be taken into consideration whenever facing patients with seizures and multiple intracranial calcifications on CT scan, for the adequate management of the diseases. 
1. Carpio A. Neurocysticercosis: an update. Lancet Infect Dis 2002;2(12):751-62. doi:10.1016/\$1473-3099(02)00454-1

2. Fabiani S, Bruschi F. Neurocysticercosis in Europe: still a public health concern not only for imported cases. Acta Trop. 2013;128(1):18-26. doi:10.1016/j.actatropica.2013.06.020

3. Carpio A, Romo M. The relationship between neurocysticercosis and epilepsy: an endless debate. Arq Neuropsiquiatr. 2014:72(5):383-90. doi:10.1590/0004-282X20140024

4. Carpio A, Placenua M. Definition of contemporary surgical management in cisternal and parenchymatous cysticercosis cerebri. Neurosurgery. 1992;30(6):968-9. doi:10.1227/00006123-199206000-00035

5. Santos GT, Leite CC, Machado LR, McKinney AM, Lucato LT. Reduced diffusion in neurocysticercosis: circumstances of appearance and possible natural history implications. AJNR Am J Neuroradiol. 2013;34(2):310-6. doi:10.3174/ajnr.A3198

6. Thurman DJ, Beghi E, Begley CE, Berg AT, Buchhalter JR, Ding D et al. Standards for epidemiologic studies and surveillance of epilepsy. Epilepsia. 2011;52 Suppl 7:S2-26. doi:10.1111/j.1528-1167.2011.03121.x

7. Carabin H, Ndimubanzi PC, Budke CM, Nguyen H, Qian Y, Cowan LD et al. Clinical manifestations associated with neurocysticercosis: a systematic review. PLoS Negl Trop Dis. 2011;5(5):e1152. doi:10.1371/journal.pntd.0001152

8. Machado LR. The diagnosis of neurocysticercosis: a closed question? Arq Neuropsiquiatr. 2010;68(1):1-2. doi:10.1590/S0004-282X2010000100001

9. Garcia HH, Nash TE, Del Brutto OH. Clinical symptoms, diagnosis and treatment of neurocysticercosis. Lancet Neurol. 2014;13(12):1202-15. doi:10.1016/S1474-4422(14)70094-8

10. Montano SM, Villaran MV, Ylquimiche L, Figueroa JJ, Rodriguez S, Bautista CT et al. Neurocysticercosis association between seizures, serology and brain CT in rural Peru. Neurology. 2005;65(2):229-33. doi:10.1212/01.wnl.0000168828.83461.09

11. Medina MT, Rosas E, Rubio-Donnadieu F, Sotelo J. Neurocysticercosis as the main cause of late-onset epilepsy in Mexico. Arch Intern Med. 1990;150(2):325-7. doi:10.1001/archinte.1990.00390140065014

12. Singh G, Singh P, Singh I, Rani A, Kaushal S, Avasthi G. Epidemiologic classification of seizures associated with neurocysticercosis: observations from a sample of seizure disorders in neurologic care in India. Acta Neurol Scand. 2006;113(4):233-40. doi:10.1111/j.1600-0404.2005.00575.x

13. Batra S, Lin D, Recinos PF, Zhang J, Rigamonti D. Cavernous malformations: natural history, diagnosis and treatment. Nat Rev Neurol. 2009;5(12):659-70. doi:10.1038/nrneurol.2009.177

14. Gross BA, Lin N, Du R, Day AL. The natural history of intracranial cavernous malformations. Neurosurg Focus 2011;30(6):E24. doi: 10.3171/2011.3.FOCUS1165

15. Al-Shahi Salman R, Hall JM, Horne MA, Moultrie F, Josephson CB, Bhattacharya JJ et al. Untreated clinical course of cerebral cavernous malformations: a prospective, population-based cohort study. Lancet Neurol. 2012;11(3):217-24. doi:10.1016/\$1474-4422(12)70004-2

16. Labauge P, Denier C, Bergametti F, Tournier-Lasserve E. Genetics of cavernous angiomas. Lancet Neurol. 2007;6(3):237-44. doi:10.1016/S1474-4422(07)70053-4

17. Mondéjar R, Solano F, Rubio R, Delgado M, Pérez-Sempere A, González-Meneses A et al. Mutation prevalence of cerebral cavernous malformation genes in Spanish patients. PLOS One. 2014;9(1):e86286. doi:10.1371/journal.pone.0086286

18. Riant F, Cecillon M, Saugier-Veber P, Tournier-Lasserve E. CCM molecular screening in a diagnosis context: novel unclassified variants leading to abnormal splicing and importance of large deletions. Neurogenetics. 2013;14(2):133-41. doi:10.1007/s10048-013-0362-0

19. Morrison L. Genetic counselling. In: Rigamonti D, editor. Cavernous malformation of the nervous system. Cambridge: Cambridge University Press; 2011. p. 181-3.
20. Choquet H, Pawlikowska L, Nelson J, McCulloch CE et al. Polymorphisms in inflammatory and immune response genes associated with cerebral cavernous malformation type 1 severity. Cerebrovasc Dis, 2014;38(6):433-40. doi:10.1159/000369200

21. Domingues F, Gasparetto EL, Andrade R, Noro F, Eiras A, Gault J et al. Familial cerebral cavernous malformations: Rio de Janeiro study and review of the recommendations for management. Arq Neuropsiquiatr. 2008;66(4):795-9. doi:10.1590/S0004-282X2008000600003

22. Shenkar R, Shi C, Rebeiz T, Stockton RA, McDonald DA, Mikati AG et al. Exceptional aggressiveness of cerebral cavernous malformation disease associated with PDCD10 mutations. Genet Med. 2015;17(3):188-96. doi:10.1038/gim.2014.97

23. Salman RA. The outlook for adults with epileptic seizures associated with cerebral cavernous malformations or arteriovenous malformations. Epilepsia. 2012;53(Suppl 4):34-42. doi:10.1111/j.1528-1167.2012.03611.x

24. Rosenow F, Alonso-Vanegas MA, Baumgartner C, Blümcke I, Carreño M, Gizewski ER et al. Cavernoma-related epilepsy: review and recommnedations for management. Report of the Surgical Task Force of the ILAE Commission on Therapeutic Strategies. Epilepsia. 2013;54(12):2025-35. doi:10.1111/epi.12402

25. Englot DJ, Han SJ, Lawton MT, Chang EF. Predictors of seizure freedom in the surgical treatment of supratentorial cavernous malformations.J Neurosurg. 2011;115(6):1169-74. doi:10.3171/2011.7.JNS11536

26. Clatterbuck RE, Eberhart CG, Crain BJ, Rigamonti D. Ultrastructural and immunocytochemical evidence that an incompetent blood-brain barrier is related to the pathophysiology of cavernous malformations.J Neurol Neurosurg Psychiatry. 2001;71(2):188-92. doi:10.1136/jnnp.71.2.188

27. Awad I, Jabbour P. Cerebral cavernous malformations and epilepsy. Neurosurg Focus. 2006;21(1):e7. doi:10.3171/foc.2006.21.1.8

28. Goodman KA, Ballagh SA, Carpio A. Case-control study of seropositivity for cysticercosis in Cuenca, Ecuador. Am J Med Hyg. 1999;60(1):70-4.

29. Lucato LT, Guedes MS, Sato JR, Bacheschi LA, Machado LR, Leite CC. The role of conventional MR imaging sequences in the evaluation of neurocysticercosis: impact on characterization of the scolex and lesion burden. AJNR Am J Neuroradiol, 2007;28(8):1501-4. doi:10.3174/ajnr.A0623

30. Santos GT, Leite CC, Machado LR, McKinney AM, Lucato LT. Reduced diffusion in neurocysticercosis: circunstances of appearance and possible natural history implications. AJNR Am J Neuroradiol. 2013;34(2):310-6. doi:10.3174/ajnr.A3198

31. Batra S, Crain B, EngelmannR, Camara-Quintana J, Rigamonti D. Pathology of cavernous malformations. In: Rigamonti D, editor. Cavernous malformation of the nervous system. Cambridge:Cambridge University Press; 2011. p 1-7.

32. Lin DDM, Abdalla W. Neuroimaging of cavernous malformation. In: Rigamonti D, editor. Cavernous malformation of the nervous system. Cambridge:Cambridge University Press; 2011. p. 49-63.

33. Souza JM, Domingues RC, Cruz LC Jr, Domingues FS, lasbeck T, Gasparetto EL. Susceptiblility-weighted imaging for the evaluation of patients with familial cerebral cavernous malformations: a comparison with T2-weighted fast spin-echo and gradient-echo sequences. AJNR Am J Neuroradiol. 2008;29(1):154-8. doi:10.3174/ajnr.A0748

34. Fleury A, Escobar A, Fragoso G, Sciutto E, Larralde C. Clinical heterogeneity of human neurocysticercosis results from complex interactions among parasytes, host and environmental factors. Trans R Soc Trop Med Hyg. 2010;104(4):243-50. doi:10.1016/j.trstmh.2010.01.005

35. Leigh R, Wityk RJ. Special problems in cavernous malformations: migraine, pregnancy, hormonal replacement, anticoagulation, NSAIDS, and altitude elevation. In: Rigamonti D, editor. Cavernous malformation of the nervous system. Cambridge:Cambridge University Press; 2011. p. 185-9.

36. Berg MJ,Vay T. Clinical features and medical management of cavernousmalformations. In: Rigamonti D, editor. Cavernous malformation of the nervous system. Cambridge: Cambridge University Press; 2011. p. 65-78. 